\title{
Combining DVR and UPS Techniques for an Uninterruptable Supply of Ultra-Sensitive Non- Linear Appliances
}

\author{
Branislav Dobrucky*, Jozef Sedo, Roman Konarik \\ Department of Mechatronics and Electronics, Faculty of Electrical Engineering, University of Zilina, \\ Univerzitna St. 1, SK-01026 Zilina, Slovakia \\ branislav.dobrucky@fel.uniza.sk
}

\begin{abstract}
The paper deals with an application of combined techniques of dynamical voltage restorer (DVR) and uninterruptible power supply (UPS) that make possible both the short voltage sags compensation, as well as longer power supply interruptions, under the simultaneous operation of equipment and network. This is enabled mainly by an instantaneous voltage sag detection, quick bidirectional overswitches, and an instantaneous control method of the output voltage. This needs a fast control method, which can provide a voltage recovery for phase-sensitive loads during several calculation steps, so the dead-beat regulator is used. Such a system even compensates for the influence of non-linear loads on the power supply network without a change of a phase and amplitude of the supply voltage. The simulation results in Matlab/Simulink, as well as real experiments and their comparison results, are given in the paper.
\end{abstract}

Index Terms-DVR device; Uninterruptible power supply; VSI converter; Quasi-instantaneous control; Dead-beat controller.

\section{INTRODUCTION}

There are many continuous production plants, such as glass production, car body paint shops, and computer tomography supply [1]-[4]. In those, the secure operation is provided by sensitive devices, among which we can include phase-sensitive appliances, such as controlled rectifiers, phase-locked loops (PLLs), selsyns and resolver devices, directly fed synchronous motors, etc. [5]-[7].

All these devices are very sensitive to voltage dips and sags occurring in distribution networks. Common means against this type of the failures are dynamic voltage restorers (DVRs), which are usually designed and dimensioned to hundreds of milliseconds for ensuring reliable operation (typically $150 \mathrm{~ms}-180 \mathrm{~ms}$ ) [8]-[10]. Against interruption and loss of supply voltage the uninterruptible power supplies (UPSs) are used which to unlike the previous ones, are designed for hours of continuous operation using accubattery as an accumulated source of energy [11]-[15]. So, each device from [8]-[10] and [11]-[15] provides compensation for different types of failures of supply for ultra-sensitive appliances. So far, there is no equipment,

Manuscript received 17 February, 2020; accepted 26 April, 2020.

The research was funded by the Grant agency APVV under a Grant (No. 15-0571 "Research of optimal control of energy flow in electric vehicle systems)". which would comprise requests provided by both DVR and UPS devices.

\section{A NEW CONCEPT OF IMPROVING RELIABILITY OF SENSITIVE APPLIANCE SUPPLY}

\section{A. Using of DVR Restorer Device to Short-Term Sags Compensation}

The single-pole block diagram of the dynamic voltage restorer is presented in Fig. 1 and Fig. 2. The short-term sags of supply voltage are reliably compensated by the DVR system.

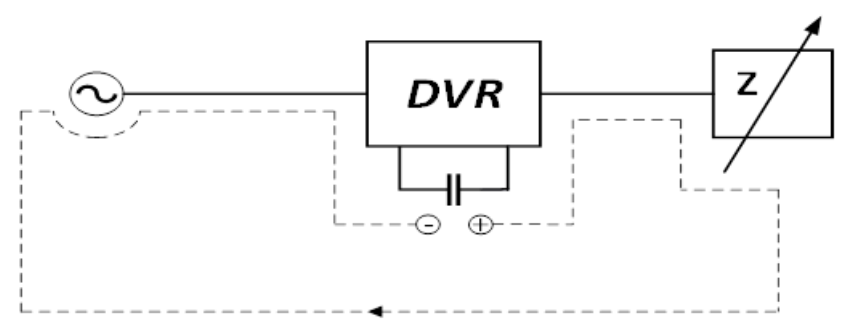

Fig. .1. Block diagram of DVR restorer (normal operation: full line; restoring operation: dashed line)

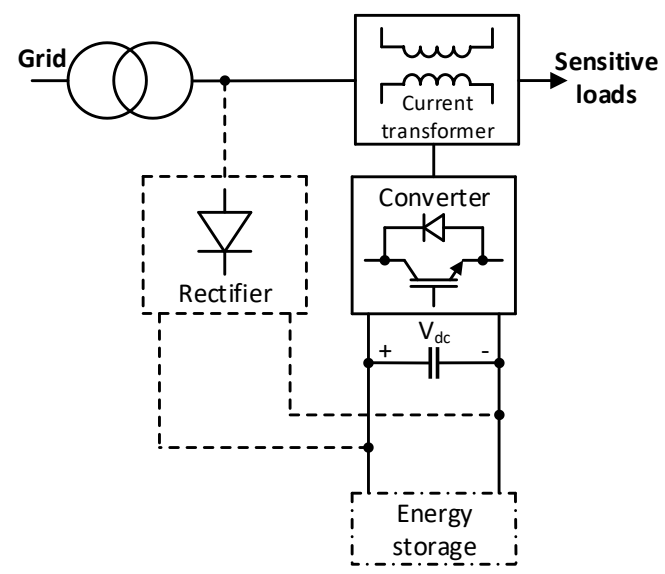

Fig. 2. Block diagram of DVR restorer (normal operation: full line; restoring operation: dashed line)

Important notes:

1. Neither a galvanic connection between network and DVR device cannot be interrupted nor shorted because of the current circuit would not be closed.

2 . The capacitor of DVR should be continuously charged by an external source, e.g., a solar photovoltaic (PV) 
system [13], [16].

B. Using of UPS Device for Uninterruptible Power Supplying of Sensitive Appliances

The single-pole block diagram of an uninterruptible power supply is presented in Fig. 3.

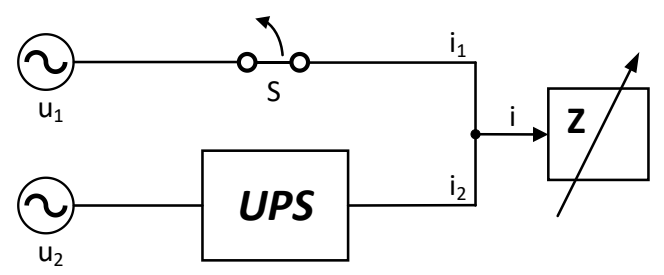

Fig. 3. Principle block diagram of UPS supply.

The accu-battery of the UPS system can be charged by either network charger or solar PV system as in the previous case.

Generally, the UPS can be operated as:

- Cold reserve;

- Hot reserve.

Anyway, it should be designed with overload capability presented by crest factor, i.e., by the ratio of the maximum and the effective (rms) value of the current (usually 2-5) to withstand overload when step-starting-up and changing load [11], [16]. As can be seen from Fig. 4, neither cold nor hot reserved UPS cannot provide to compensate requested voltage sags interruption in all possible cases.

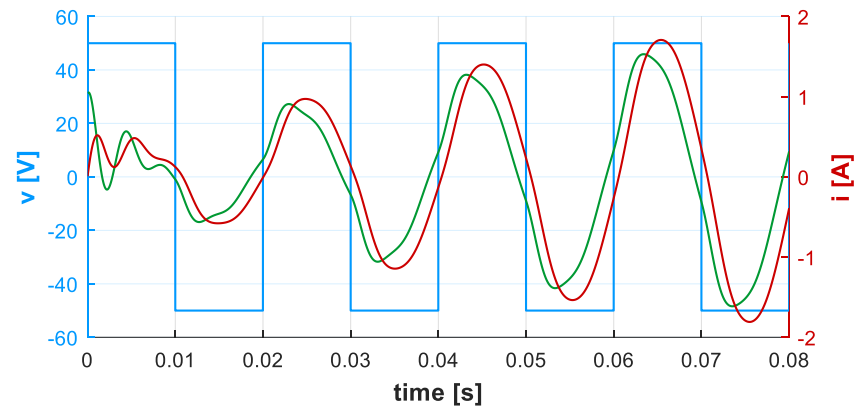

Fig. 4. The step-change of linear $R-L$ load from 0 to $100 \%$.

In both systems $A$ and $B$, the critical part is the detection of voltage sags because it should be very fast [17]-[22], [33]. One of the most effective approaches is based on sensing of $d-q$ voltages and consequently comparing to referenced values (Fig. 5).

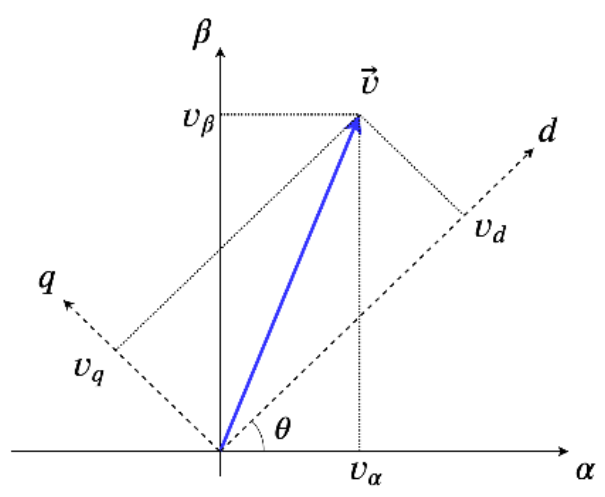

Fig. 5. Determination of instantaneous voltage in $d$ - $q$ coordinates.

System $d-q$ voltage determination is as follows

$$
\left[\begin{array}{l}
v_{d} \\
v_{q}
\end{array}\right]=e^{j \omega t}\left[\begin{array}{l}
v_{\alpha} \\
v_{\beta}
\end{array}\right]=\left[\begin{array}{cc}
\sin (\omega t) & \cos (\omega t) \\
\cos (\omega t) & -\sin (\omega t)
\end{array}\right]\left[\begin{array}{c}
v_{\alpha} \\
v_{\beta}
\end{array}\right],
$$

where $v_{d}$ and $v_{q}$ will be constants, and the module of a $d$ - $q$ voltage will be also a constant $(D C)$ value

$$
v_{\text {ref }}=\sqrt{v_{d}^{2}+v_{q}^{2}}=\sqrt{v_{\alpha}^{2}+v_{\beta}^{2}}=\text { const. }
$$

So, consequently compared actual and reference values can be provided by a single voltage comparator.

\section{A New Concept of Improving Reliability under Non-linear Loads}

A new concept of improving the reliability of sensitive appliance supply has been proposed, which combines both DVR and UPS techniques mentioned above. The concept is based on the following ideas:

- Both energetic sources will be operated in parallel, so during switching-off of their failure part, no time delay will occur;

- Sensitive devices will be permanently connected to the UPS, so no start-up transient problems will arise thanks to the fast dead-beat current controller of UPS part;

- The current distribution between the power supply and the UPS will be 1:1 maintained by the UPS voltage control system.

The single-pole block diagram of a new concept of improving reliability is presented in Fig. 6.

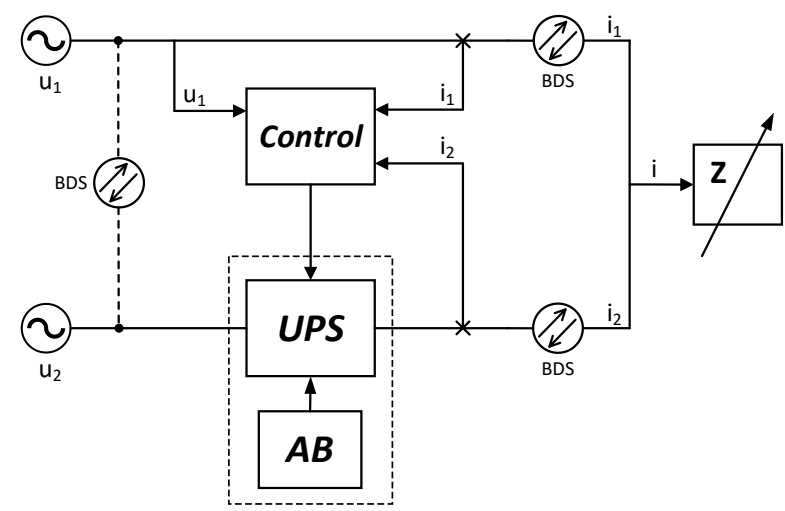

(a)

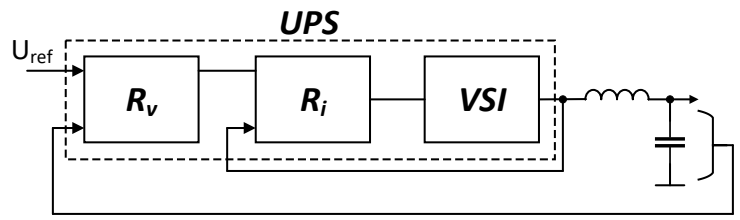

(b)

Fig. 6. (a) New concept block diagram combining DVR and UPS techniques, and (b) DB controlled UPS $\left(R_{i}-\right.$ current controller type of dead-beat).

The simulation experiments of this scheme and simulation results are given in Section III.

\section{D.Estimated a Mean Time between Failures - Improving Reliability}

Regarding UPS operation, as stated, neither booked nor cold or hot booked UPS need to provide compensation for the interruption of the required voltage drop caused by some transient phenomenon (Fig. 3), which could lead to 
malfunctioning of the sensitive load and interruption of supply. On the other hand, if the UPS is equipped with a battery of adequate capacity, even faulty network operation may not lead to a loss of power supply for sensitive loads, since the energy required by the sensitive load will be provided by the battery (Fig. 7).

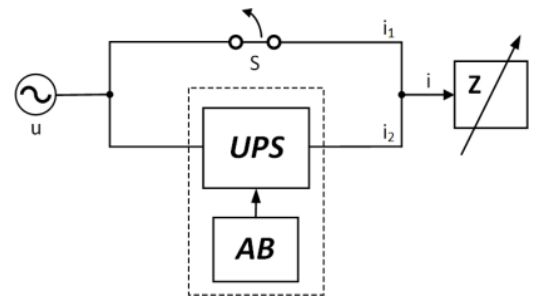

Fig. 7. Principle block diagram using UPS for operation reliability calculation.
A device with several independent power supplies has the best reliability of operation, but this is the most expensive solution [23], [24]. The UPS connection has a better operational reliability value $\mathrm{R}(\mathrm{t})$ than a single power supply. The UPS application with battery can increase the mean time between failures (MTBF) by 3.94 times. The new conceptual solution with UPS, battery packs, and instant DBC control achieves up to MTBF of two parallel power supplies (approximately $10^{6}$ hours), far more than a single UPS solution (approximately $10^{4}$ hours) [25].

\section{MODELING AND Simulation}

The actual Simulink schematic is shown in Fig. 8. The sensitive non-linear appliance is presented by a rectifier with a capacitive output filter [15], [28].

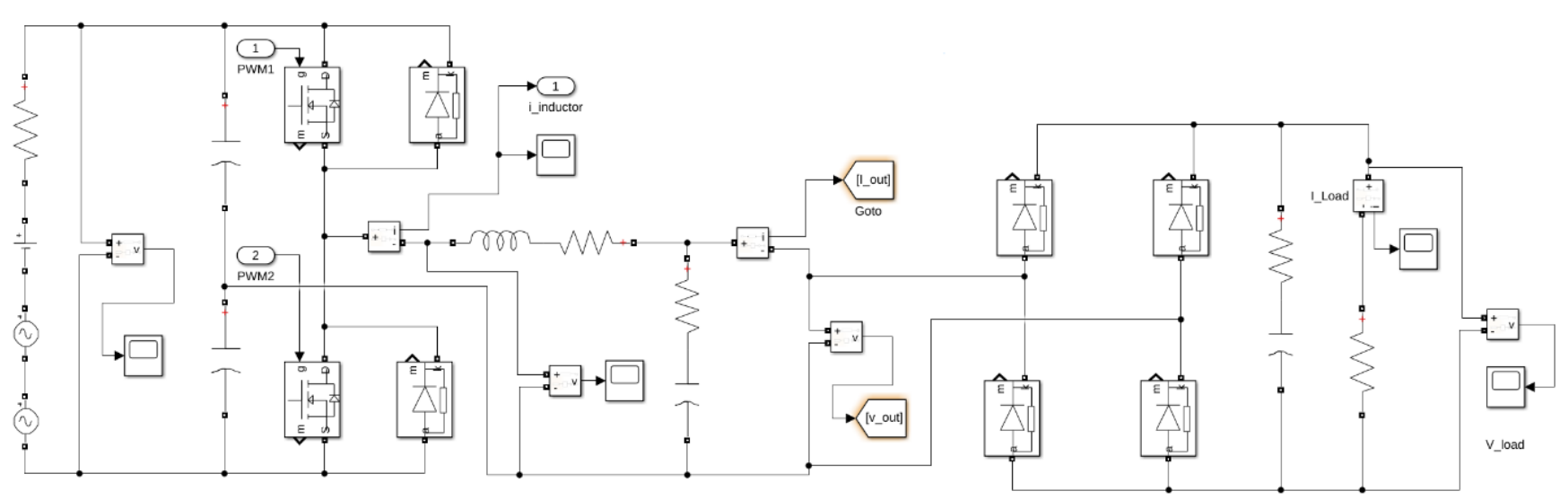

Fig. 8. Simulink model of half-bridge voltage source inverter (VSI) with diode rectifier and capacitive filter.

\section{A. Design of Inner Control Loop - Non-Linear Load}

If the load is non-linear (non-harmonic), a novel approach with a proportional integral (PI) controller (outer voltage loop) and a DB controller (inner current loop) should be used [26], [27]. Generally, we do not know the nature of the load supposing non-linear one. Since we know the disturbance variable $u_{\text {out }}(k)$ itself, we can compensate its influence (the error will be zero) by adding the $u_{\text {out }}(k)$ to the output signal of the controller. Then, we can define the current loop control algorithm as

$$
v_{a_{-} r e f}(k)=D B\left[i_{\text {Lref }}(k)-i_{L}(k)\right]+v_{\text {out }}(k),
$$

where $i_{\text {Lref }}$ is the inductor current reference value, $i_{L}(k)$ is the inductance actual value, $v_{\text {out }}(k)$ is the actual output voltage value, $v_{a \_ \text {ref }}(k)$ is the calculated voltage value that enters the pulse-width modulation (PWM) modulator as a modulation signal (Fig. 9(a)).

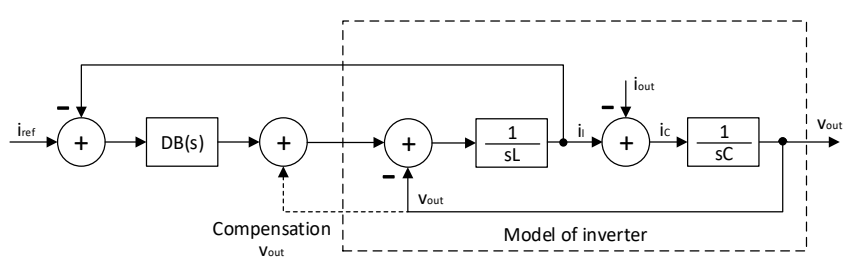

(a)

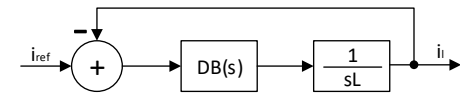

(b)

Fig. 9. (a) Block scheme of the current loop and (b) simplified loop.

As shown in Fig. 9(b), the current loop has been simplified by compensating for the effect of the output voltage. We get a single-loop feedback circuit. The control circuit with a dead-beat controller has the following characteristics:

- Zero regulatory deviation;

- Minimum start-up time;

- The minimum period of regulation, supposing that the variable can reach high values.

The input to the controller design is the transfer function of the continuous plant

$$
G_{P}(s)=\frac{b_{n} s^{n}+\cdots+b_{1} s+b_{0}}{a_{n} s^{n}+\cdots+a_{1} s+a_{0}} e^{-D s},
$$

where $a_{\mathrm{n}}, b_{\mathrm{n}}$ are continuous transfer coefficients and $D$ is a traffic delay. When transferring discretization, we use the zero-order hold [29]. The discrete form of the transfer function is 


$$
G_{P}(z)=\frac{B(z)}{A(z)}=\frac{b_{1} z^{-1}+\cdots+b_{m} z^{-m}}{1+a_{1} z^{-1}+\cdots+a_{m} z^{-m}}=\frac{Y(z)}{U(z)} .
$$

The design of the controller is based on the system model shown in Fig. 9(b). Specific parameter values are:

$-\Delta T=40[\mu \mathrm{s}]$

$-L=1.3[\mathrm{mH}]$.

The transfer function of a continuous model will be

$$
G_{P}(s)=\frac{1}{s L}=\frac{1}{0.0013 s} .
$$

Using definition relations of z-transform, we get a discrete transfer function

$$
G_{P}(z)=\frac{0.03077}{z-1}, \text { resp. } \frac{0.03077 z}{z-1} \text { or } \frac{0.03077(z+1)}{2(z-1)}
$$

Using the previously described relationships, we get the coefficients of the regulator

$$
G_{R}(z)=\frac{32.5 z-32.5}{z-1}
$$

or others depending on $G_{p}(z)$ as given in (7).

The total transmission of the closed-loop control is

$$
G_{Y / W}(z)=\frac{G_{R}(z) G_{P}(z)}{1+G_{R}(z) G_{P}(z)}=\frac{1}{z},
$$

where do we get the difference equation

$$
\begin{gathered}
u(k)=q_{0} e(k)+q_{1} e(k-1)+\cdots+q_{m} e(k-m)+ \\
+p_{1} u(k-1)+p_{2} u(k-2)+\cdots+p_{m} u(k-m) .
\end{gathered}
$$

To verify the correctness of the design of this controller, we performed a simulation analysis in Matlab/Simulink (see Fig. 10).

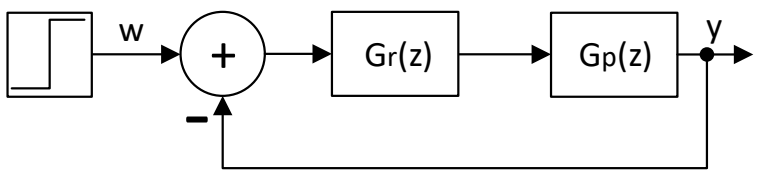

Fig. 10. The control scheme for confirmation of DB regulator design.

As shown in the next Fig. 11, the output variable of the control circuit is delayed by the control variable by two sampling periods. This delay complies with the following assumptions.

\section{B. Design of Outer Control Loop - Voltage Loop}

Since the load dynamics are unknown to us, the load current behaves as a failure quantity acting on the inverter output voltage. Therefore, we can take this current as a feedback signal and add it to the control variable. This eliminates the failure effect on the output voltage and the resulting voltage loop is simplified (Fig. 12) [29]-[32].

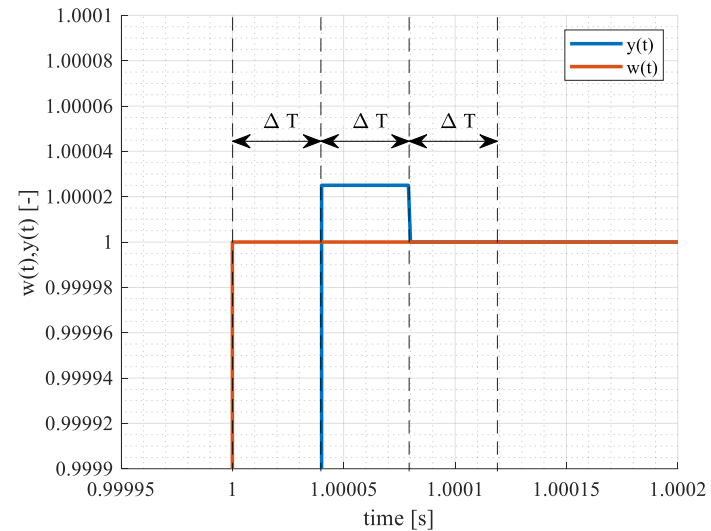

Fig. 11. The response of manipulating variable to step-change of reference value.

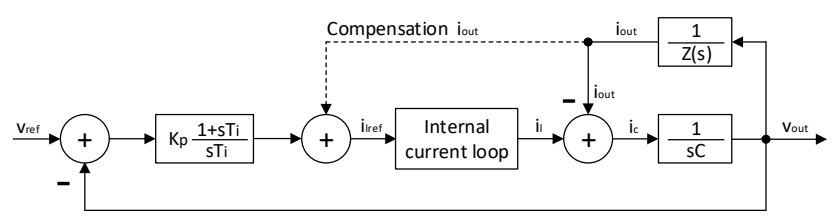

(a)

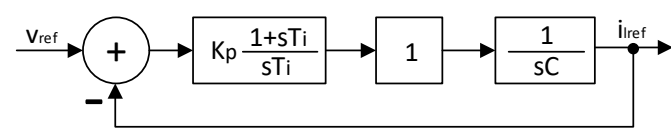

(b)

Fig. 12. Block diagram: (a) voltage loop, (b) simplified voltage loop.

Since we used the dead-beat controller to design the controller for the internal current loop, which monitors the reference signal with the least delay, we can neglect its dynamics in the design of the voltage loop and consider this loop constant. Then, the voltage loop control algorithm is defined by

$$
i_{\text {Lref }}=\left(K_{p}+\frac{1}{s T_{i}}\right) \times\left(v_{\text {ref }}(k)-v_{\text {out }}(k)\right)+i_{\text {out }}(k),
$$

wherein $v_{\text {ref }}(k)$ represents a sinusoidal reference signal for a voltage loop and $i_{\text {Lref }}(k)$ represents a reference signal for an internal current loop.

We do regulator synthesis using the pole placement method described in [31], [32]. The main idea behind this method is to force the transmission of the system to the poles chosen by us to determine its dynamic behavior. The disadvantage is that the method does not specify a system reader. Therefore, any zeros of the transfer may aggravate its dynamics. Therefore, we will also introduce compensation for the effect of these zeros on the system. The general $\mathrm{n}^{\text {th }}$ order transfer is defined by the relation (12), and the $\mathrm{n}^{\text {th }}$ order general controller transfer is defined by the relation (13):

$$
\begin{aligned}
& G_{P}(s)=\frac{b_{n-1} s^{n-1}+\cdots+b_{1} s+b_{0}}{s^{n}+a_{n-1} s^{n-1}+\cdots+a_{1} s+a_{0}}, \\
& G_{R}(s)=\frac{d_{m} s^{m}+\cdots+d_{1} s+d_{0}}{s^{m}+c_{m-1} s^{m-1}+\cdots+c_{1} s+c_{0}} .
\end{aligned}
$$


The control circuit transmission is then given by the feedback circuit $G_{R}(s)$ and $G_{p}(s)$

$$
G(s)=\frac{G_{R}(s) G_{P}(s)}{1+G_{R}(s) G_{P}(s)} .
$$

We place a characteristic transfer equation $G(s)$ equal to the general transmission of the same order as the characteristic equation

$$
\begin{aligned}
& s^{n}+a_{n-1} \times s^{n-1}+\cdots+a_{1} \times s+a_{0}= \\
& =s^{n}+\tilde{a}_{n-1} \times s^{n-1}+\cdots+\tilde{a}_{1} \times s+\tilde{a}_{0} .
\end{aligned}
$$

By comparing the coefficients of the polynomials on the left and right sides of the relationship (15) we get a system of $n$ equations, from which we calculate unknown parameters of the regulator, which act as unknown in the coefficients $\tilde{a}_{\mathrm{n}-1}, \ldots, \tilde{a}_{0}$. An undesirable zero in the numerator appears in the transmission of the system causing the output quantity overshoots. We, therefore, compensate for this zero. Then, the control scheme changes as shown in Fig. 13 [29], [31], [32].

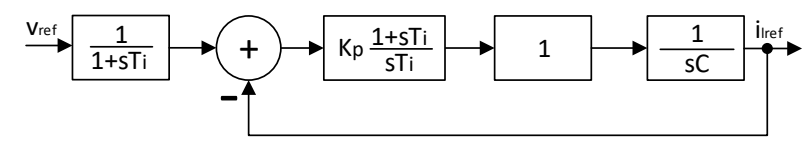

Fig. 13. Compensation of zero of the transfer function.

The regulated system is represented by the simple feedback circuit of Fig. 12. Then, the transmission of the system is given as (relationship assistance)

$$
G_{P}(s)=\frac{1}{s C}=\frac{1}{24.7 \times 10^{-6} s} .
$$

As a controller, we have selected a PI controller, whose relationship is given by (17)

$$
G_{R}(s)=\frac{K_{p} T_{i} s+K_{p}}{T_{i} s} .
$$

The resulting control circuit transfer is given by the relationship

$$
G(s)=\frac{G_{R}(s) G_{P}(s)}{1+G_{R}(s) G_{P}(s)}=\frac{\frac{K_{p}}{T_{i} C}\left(T_{i} s+1\right)}{s^{2}+\frac{K_{p}}{C} s+\frac{K_{p}}{T_{i} C}} .
$$

According to this, we introduce the transfer zero compensation $G(s)$. Then, the relationship is to be

$$
\begin{gathered}
G(s)=\frac{1}{T_{i} s+1} \times \frac{G_{R}(s) G_{P}(s)}{1+G_{R}(s) G_{P}(s)}= \\
=\frac{1}{T_{i} s+1} \times \frac{\frac{K_{p}}{T_{i} C}\left(T_{i} s+1\right)}{s^{2}+\frac{K_{p}}{C} s+\frac{K_{p}}{T_{i} C}}=\frac{\frac{K_{p}}{T_{i} C}}{s^{2}+\frac{K_{p}}{C} s+\frac{K_{p}}{T_{i} C}} .
\end{gathered}
$$

The second-order transfer function is defined as

$$
s^{2}+2 \xi \omega_{0} s+\omega_{0}^{2}
$$

By comparing the transmission coefficients of our system to the second-order system, we obtain the resulting coefficients of the $P I$ controller $\left(K_{p}\right.$ the gain and $T_{i}$ the time constant):

$$
\begin{gathered}
K_{p}=2 C \xi \omega_{0}, \\
T_{i}=\frac{K_{p}}{\omega_{0}^{2} C},
\end{gathered}
$$

where, $\xi$ represents the damping of the circuit, $w_{0}$ is the natural frequency of the circuit. This can be defined by the Dodds relationship [16], [31]. This is defined by the relationship

$$
T_{\text {reg }}=1.5(1+n) \frac{1}{\omega_{0}} .
$$

Then, the natural frequency is expressed as

$$
\omega_{0}=1.5(1+n) \frac{1}{T_{\text {reg }}} .
$$

Settling time $T_{\text {reg }}$ we determined from simulation experiments. We set its value to $0.01 \times 10^{-3} \mathrm{~s}$. After substituting this value into the previous relations, we get the gain values $K_{p}=22.23$ and the value of the time integration constant $T_{i}=4.4 \times 10^{-6} \mathrm{~s}$ :

$$
\begin{aligned}
& G_{R}(s)=\frac{9.81 \times 10^{-5} s+22.3}{4.4 \times 10^{-6} s}, \\
& G_{K O M P}(s)=\frac{1}{4.4 \times 10^{-6} s+1} .
\end{aligned}
$$

The whole control circuit transfer is then given by feedback of $G_{R}(s), G_{p}(s)$, and $G_{K O M P}(s)$

$$
G(s)=G_{K O M P}(s) \frac{G_{R}(s) G_{P}(s)}{1+G_{R}(s) G_{P}(s)} .
$$

For use in our proposed control structure, we still need to design the PI controller and zero compensator to be discrete. When transferring, we use zero-order shaper. Then, the controller and compensator transmission has the form:

$$
\begin{gathered}
G_{R}(z)=\frac{22.30 z+177.84}{z-1}, \\
G_{K O M P}(z)=\frac{0.999}{z-1.23 \times 10^{-4}} .
\end{gathered}
$$

And a plant transfer

$$
G_{P}(z)=\frac{40 \times 10^{-6}}{24.7 \times 10^{-6}} \frac{1}{z-1}=\frac{1.62}{z-1}
$$

Then, the whole control circuit transfer is given by 
feedback of $G_{R}(z), G_{p}(z)$, and $G_{K O M P}(z)$

$$
G(z)=G_{K O M P}(z) \frac{G_{R}(z) G_{P}(z)}{1+G_{R}(z) G_{P}(z)} .
$$

Note: In the practical implementation of digital control by employing a microcomputer, the transfer function of the $G_{R}(z)$ the controller is not used, but is converted to a difference equation.

\section{SIMULATION RESULTS AND EXPERIMENTAL VERIFICATION}

The experimental setup follows the configuration in Fig. 6(a) and its Simulink diagram in Fig. 8. The UPS stage comprises single-phase insulated-gate bipolar transistor (IGBT) VSI fed by accu-battery (AB) or by the network. The bidirectional switches integrated bootstrap diode (BSD) are anti-reverse connected IGBT, similarly to those used in matrix converters. The load L was presented either linear pure resistive or resistive-inductive ones or capacitive rectifier as non-linear one.

Simulation results for linear and non-linear load capacitive rectifier are shown in Figs. 14-18. To control the experiments, the digital signal controller (DSC) of Texas Instruments TMSC320F28335 was used [34]. The LEM sensor LV25-P has been used as the voltage and the Honeywell CSNR151 as a current sensor.

System parameters used for simulation and experimental verification:

- DC link voltage $V_{D C}=670 \mathrm{~V}$;

- Output voltage $V_{\text {out }(r m s)}=110 \mathrm{~V}$;

- Output power $P_{\text {out }}=1 \mathrm{~kW}$;

- Filter inductance $L_{\text {filter }}=1.3 \mathrm{mH}$;

- Filter capacity $C_{\text {filter }}=24.7 \mu \mathrm{F}$;

- Base frequency $f_{\text {base }}=50 \mathrm{~Hz}$;

- Load resistor $R=5.98 \Omega$;

- Load inductance $L=33.5 \mathrm{mH}$.

Sampling and switching frequency are equal to $25 \mathrm{kHz}$.

\section{A. Parallel Operation of the UPS and Network}

Simulation of grid voltage disconnection presenting the step-change of linear resistive load from $50 \%$ to $100 \%$ during the parallel operation of the UPS and network is shown in Fig. 14.

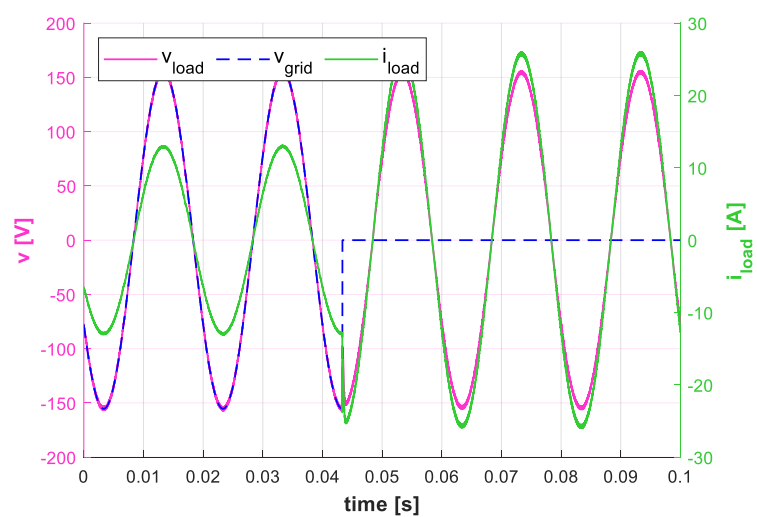

Fig. 14. The step-change of linear resistive load from $50 \%$ to $100 \%$ at the maximum of the $v_{\text {load }}$.

Simulation of grid voltage disconnection presenting the step-change of linear inductive load from $50 \%$ to $100 \%$ during the parallel operation of the UPS and network is shown in Fig. 15.

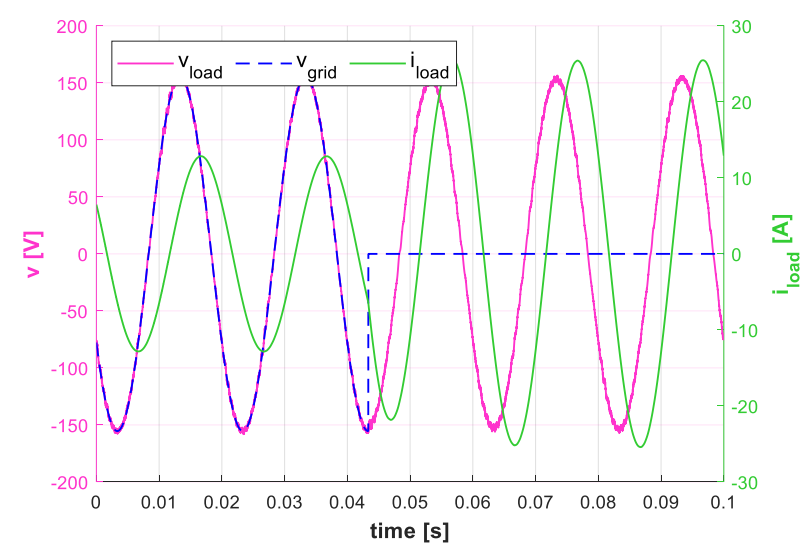

Fig. 15 .The step-change of linear inductive load from $50 \%$ to $100 \%$ at the maximum of the $v_{\text {load }}$.

\section{B. Non-Linear Load - Capacitive Rectifier}

Simulation results of grid voltage disconnection presenting the step change of non-linear load from $50 \%$ to $100 \%$ during the parallel operation of the UPS and network are shown in Fig. 16. The step-change is done at the maximum of the $v_{\text {load }}=v_{\text {grig }}$ from $50 \%$ to $100 \%$ of the load.

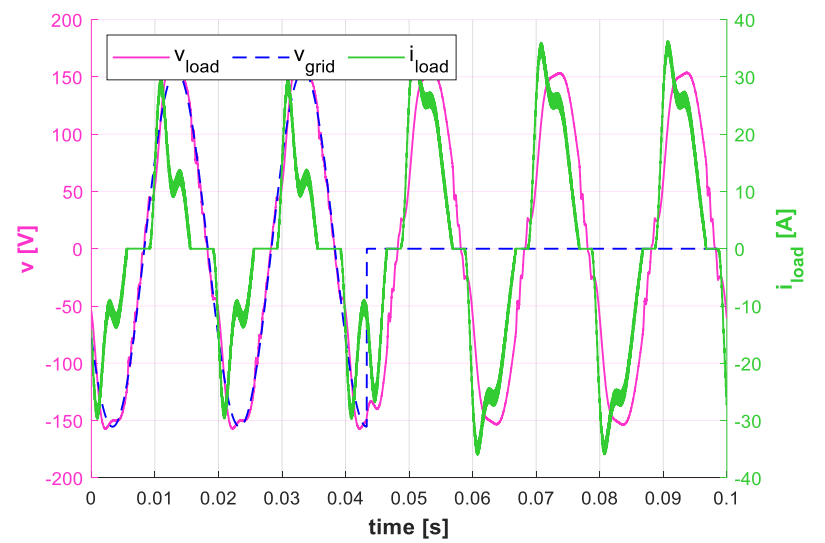

Fig. 16. Output voltage and current during parallel operation of the UPS (with DB controller) and network under capacitive rectifier of 50\%-100\% load.

\section{Linear Load - Resistive and Inductive Ones: Step- Changes of the Load from $0 \%$ to $100 \%$}

Simulation of a step-change of linear resistive load from $0 \%$ to $100 \%$ is shown in Fig. 17.

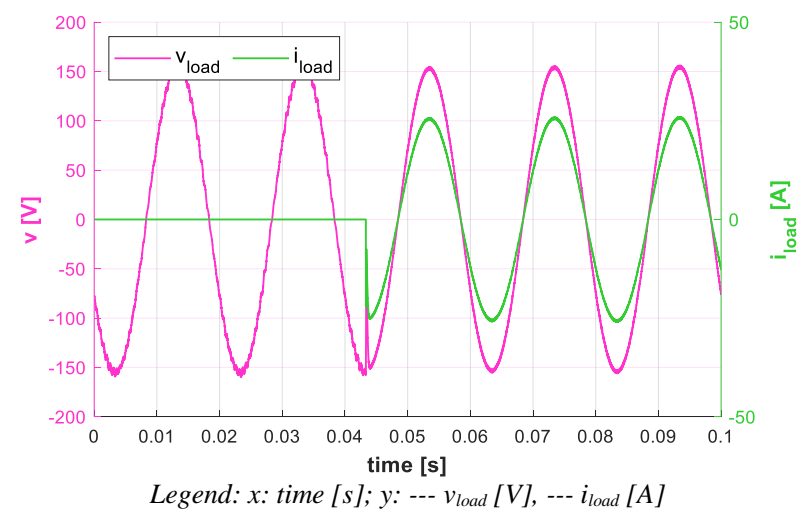

Fig. 17. The step-change of linear resistive load from $0 \%$ to $100 \%$. 
Simulation of step-change of linear inductive load from $0 \%$ to $100 \%$ is shown in Fig. 18.

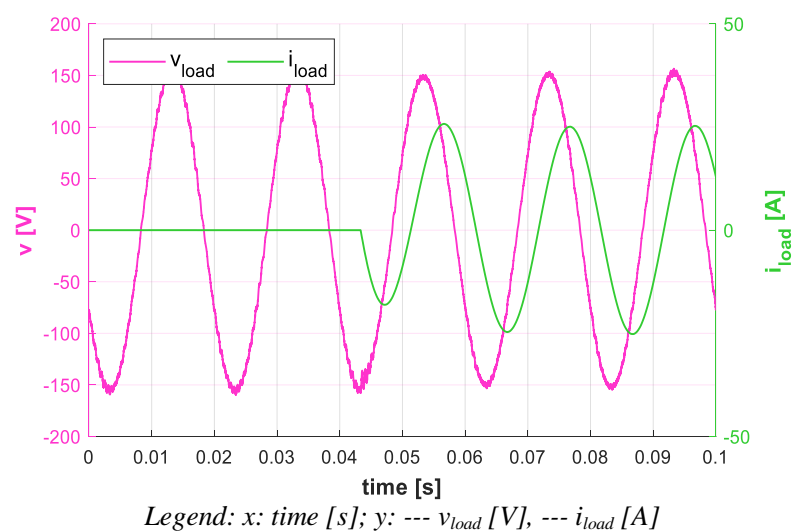

Fig. 18. Step-change of linear inductive load from $0 \%$ to $100 \%$.

\section{Experimental Verification (Figs. 19-21)}

Experiment of the step-change of linear inductive load from $0 \%$ to $100 \%$ is shown in Fig. 19.

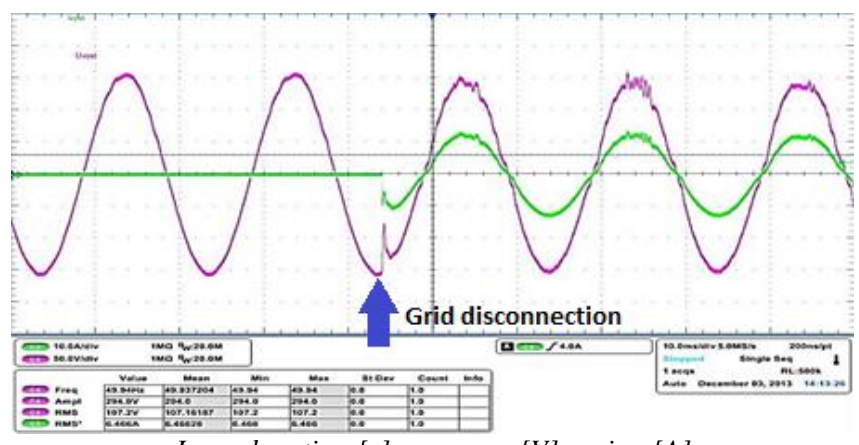

Legend: $x$ : time $[s] ; y:--v_{\text {load }}[V],--i_{\text {load }}[A]$
Fig. 19. Step-change of linear resistive load from $0 \%$ to $100 \%$ : experiment.

Experiment of the step-change of linear inductive load from $0 \%$ to $100 \%$ is shown in Fig. 20.

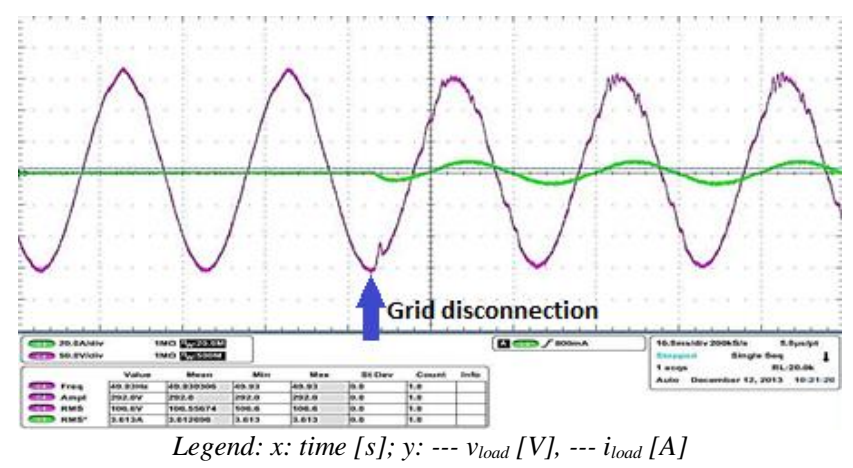

Fig. 20. Step-change of linear inductive load from $0 \%$ to $100 \%$ : experiment.

Simulation result of grid voltage disconnection presenting the step change of non-linear load from $50 \%$ to $100 \%$ during the parallel operation of the UPS and network is shown in Fig. 21. The step-change is done at the maximum of the $v_{\text {load }}=v_{\text {grig }}$ from $50 \%$ to $100 \%$ of the load.

As can be seen from Fig. 14 and Fig. 17, the comparison shows good properties during network interruptions. The comparison of simulation results and experimental ones in Fig. 17 and Fig. 18 and Fig. 19 and Fig. 20 is in good agreement. Similarly, circumstances under non-linear load, Fig. 16 and Fig. 21, represent the good quality of investigated waveforms.

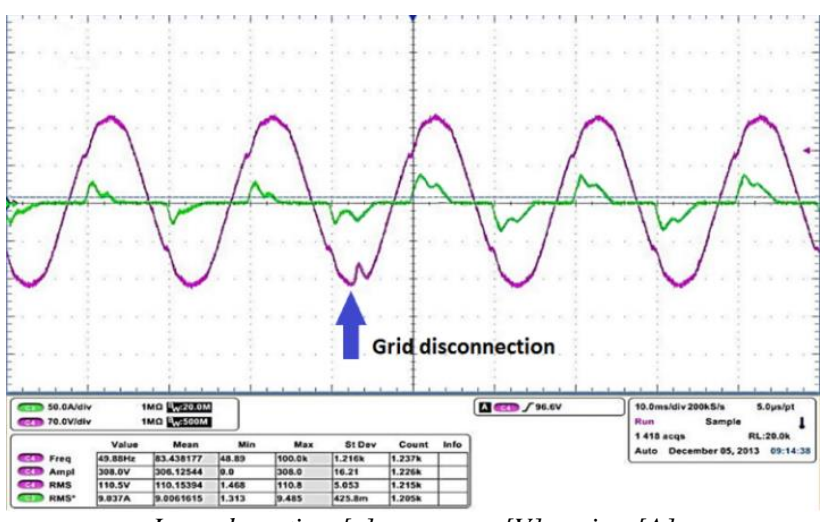

Legend: $x$ - time $[s] ; y-\cdots v_{\text {load }}[V],--i_{\text {load }}[A]$

Fig. 21. Output voltage and current during parallel operation of the UPS (with DB controller) and network under capacitive rectifier of 50\%-100\% load: experiment.

\section{V.CONCLUSIONS}

The combined technique of dynamical voltage restorer (DVR) and uninterruptible power supply (UPS) providing compensation for the short-term voltage sags, as well as longer network interruption, have been introduced. Comparison of simulation and experimental results show a good agreement and the good quality confirmed for nonlinear loads also. In all cases of a linear or full non-linear load, the difference between the measured and the simulated waveform of the output voltage reaches $2.15 \%$, regarding total harmonic distortion (THD). This is enabled mainly by an instantaneous voltage sag detection, quick bidirectional over-switches, and an instantaneous control method of the output voltage as shown in Fig. 6(a). Using the dead-beat regulator, a voltage recovery during several calculation steps is provided due to the fast control method and can be used for ultra-sensitive loads. Simultaneously, the improvement of a secured supply of ultra-sensitive appliances in the AC network is provided.

\section{CONFLICTS OF INTEREST}

The authors declare that they have no conflicts of interest.

\section{REFERENCES}

[1] E. Möllerstedt and B. Bernhardsson, "Out of control because of harmonics-An analysis of the harmonic response of an inverter locomotive", IEEE Control Syst. Mag., vol. 20, no. 4, pp. 70-81, Aug. 2000. DOI: 10.1109/37.856180.

[2] H. Saad and Y. Fillion, "Analysis of harmonics and resonances in HVDC-MMC link connected to AC grid", in Proc. of International Conference on Power Systems Transients (IPST2017) [CD-ROM], Seoul, Republic of Korea, Jun. 2017. DOI 10.1109/TPWRD.2017.2648887.

[3] A. J. Roscoe, R. Carter, A. Cruden, and G. M. Burt, "Fast responding measurement of power system harmonics using discrete and fast Fourier transforms with low spectral leakage", in Proc. of the IET Conference on Renewable Power Generation, Edinburg, UK, 2011, p. 103. DOI: $10.1049 / \mathrm{cp} .2011 .0140$.

[4] M. Meyer, "Network stability in big railway nets", (in German) Schweizer Eisenbahn-Revue, no. 7-8, pp. 312-317, 1999.

[5] B. Dobrucky, M. Pokorny, and M. Benova, "Interaction of renewable energy source and power supply network", in Renewable Energy Book. IN-TECH Education and Publishing KG, Vienna (AT), 2009, pp. 197-210. DOI: 10.5772/7371.

[6] A. Rostami, J. Olamaei, and H. Abdi, "Islanding detection of synchronous DG based on inherent feature extracted from mechanical power", Iranian Journal of Science and Technology, Transactions of 
Electrical Engineering, vol. 43, pp. 919-928, 2019. DOI: 10.1007/s40998-019-00193-8.

[7] B. Dobrucky, M. Pokorny, R. Pavlanin, and M. Luskova, "Real-time FPGA-HIL simulation helps to electrical energy supply management", in Proc. of MEI International Conf.[CD-ROM], Orlando (FL, USA), Jun. 2009.

[8] V. K. Remya, P. Parthiban, V. Ansal, and B. Chitti Babu, "Dynamic voltage restorer (DVR)-A review", Journal of Green Engineering, vol. 8, no. 4, pp. 519-572, Oct. 2018. DOI: 10.13052/jge19044720.844 .

[9] B. Dobrucky, P. Spanik, and M. Pokorny, "Dynamic single-phase DVR system with instantaneous power factor estimator", IREE International review of electrical engineering, vol. 3, no. 1, pp. 9-16, Jan.-Feb. 2008.

[10] P. Hecko, "Voltage dip and interruption compensation in 110/25 kV electric substation", Ph.D. dissertation, Faculty of Electrical Engineering, University of Zilina, Zilina, Slovak Republic, 2010.

[11] O. Kukrer, H. Komurcugil, and N. S. Bayindir, "Control strategy for single-phase UPS inverters", IEE Proceedings - Electric Power Applications, vol. 150, no. 6, pp. 743-746, 2003. DOI: 10.1049/ipepa:20030732.

[12] M. Valco, J. Sedo, and M. Paskala, "Simulation analysis of DC/AC inverter under nonlinear load", in Proc. of the 21th Technical Computing International Conference, Prague, CZ, 2013, pp. 334-340.

[13] M. Frivaldsky, J. Morgos, and A. Kanovsky, "Dual interleaved LLC converter for high power applications and wide load range", Elektronika ir Elektrotechnika, vol. 25, no. 3, pp. 4-9, 2019. DOI: 10.5755/j01.eie.25.3.23669.

[14] M. Cacciato, A. Consoli, R. Attanasio, and F. Gennaro, "Softswitching converter with HF transformer for grid-connected photovoltaic systems", IEEE Transactions on Industrial Electronics, vol. 57, no. 5, May 2010. DOI: 10.1109/TIE.2009.2032201.

[15] M. Valco, "Single-phase voltage source inverter with adjustable instantaneous output voltage for supplying of nonlinear loads" (in Slovak), Ph.D. dissertation, Faculty of Electrical Engineering, University of Zilina, Zilina, Slovak Republic, 2014.

[16] R. Singh, M. Kumar, and H. Ashfaq, "An integrated solar photovoltaic and dynamic voltage restorer for load voltage compensation", International Journal of Electrical Engineering \& Technology (IJEET), vol. 9, no. 5, pp. 52-63, Sept.-Oct. 2018.

[17] A. Otcenasova, J. Altus, P. Hecko, and M. Roch, "Measurement characteristics of voltage in practice and possibilities for improvement of voltage", Przeglad elektrotechnniczny (Electrical Review), vol. 88, no. 9a, pp. 103-106, 2012.

[18] E. Styvaktakis, I. Y. H. Gu, and M. H. J. Bollen, "Voltage dip detection and power system transients", in Proc. of 2001 Power Engineering Society Summer Meeting, Vancouver, Canada, 2001, pp. 683-688. DOI: 10.1109/PESS.2001.970124.

[19] B. Bae, J. Jeong, J. Lee, and B. Han, "Novel sag detection method for line-interactive dynamic voltage restorer", IEEE Transactions on Power Delivery, vol. 25, no. 2, pp. 1210-1211, 2010. DOI: 10.1109/TPWRD.2009.2037520.

[20] M. Inci, K. Ç. Bayindir, and M. Tümay, "Improved synchronous reference frame based controller method for multifunctional compensation", Electric Power System Research, vol. 141, pp. 500509, 2016. DOI: 10.1016/j.epsr.2016.08.033.

[21] A. K. Sadigh and K. M. Smedley, "Fast and precise voltage sag detection method for dynamic voltage restorer (DVR) application", Electric Power Systems Research, vol. 130, pp. 192-207, 2016. DOI: 10.1016/j.epsr.2015.08.002.

[22] A. Kawamura, T. Haneyoshi, and R. G. Hoft, "Deadbeat controlled PWM inverter with parameter estimation using only voltage sensor", IEEE Transactions on Power Electronics, vol. 3, no. 2, pp. 118-125, Apr. 1988. DOI: 10.1109/63.4341.

[23] "Annual report on reliability standards of power distribution for the year 2018 (in Slovak)", Middle-Slovak Distribution, Ltd. Stredoslovenská distribučná. [Online]. Available: https://www.ssd.sk/o-spolocnosti?page_id=3895

[24] J. B. Sor, Practicle Problems of Reliability Theory (in Czech). Prague, ČVUT, 1987.

[25] B. Dobrucky, J. Sedo, P. Bracinik, and M. Luskova, "Improving reliability of sensitive appliance supply combining DVR and UPS techniques: A new concept", in Proc. of ELEKTRO 2020 International Conf., Taormina (IT), 2020, unpublished.

[26] O. Kukrer and H. Komurcugil, "Deadbeat control method for singlephase UPS inverters with compensation of computation delay", IEE Electric Power Applications, vol. 146, pp. 123-128, 1999. DOI: 10.1049/ip-epa:19990215.

[27] C.-T. Chen, "State feedback, state estimator, and dead-beat design", in Analog and Digital Control System Design - Transfer-Function, State-Space and Algebraic Methods. Oxford University Press, New York, USA, 1993, pp. 541-544.

[28] K. Hyosung and S. Seung-Ki, "A novel filter design for output LC filters of PWM inverters", Journal of Power Electronics, vol. 11, pp. 74-81, 2011. DOI: 10.6113/JPE.2011.11.1.074.

[29] H. Guozhen, M. Ling, L. Jun, Zh. Lei, F. Zh. Jian, "Stability analysis of multi-inverters grid-connected system using improved current source impedance ratio criterion", Elektronika ir Elektrotechnika, vol. 25, no. 2, pp. 14-19, 2019. DOI: 10.5755/j01.eie.25.2.23198.

[30] O. Kukrer, H. Komurcugil, and N. S. Bayindir, "Control strategy for single-phase UPS inverters", IEE Electric Power Applications, vol. 150, pp. 743-746, 2003. DOI: 10.1049/ip-epa:20030732.

[31] P. Makyš and M. Štulrajter, "Creation of simulation model with one degree of freedom", Final report, Research center of mechatronics systems, 2008

[32] A. Goudarzian and A. Khosravi, "Voltage regulation of a negative output luo converter using a PD-PI type sliding mode current controller", International Journal of Engineering (IJE), Transactions B: Applications, vol. 32, no. 2, pp. 277-285, 2019. DOI: 10.5829/ije.2019.32.02b.13.

[33] J. Ren, Y. Sun, Sh. Zhang, Sh. Zhang, Y. Liu, K. Li, and X. Jiang, "A novel self-powered smart current sensor for power equipment", Elektronika ir Elektrotechnika, vol. 25, no. 2, pp. 20-27, 2019. DOI: 10.5755/j01.eie.25.2.23199.

[34] TMS320F28335. [Online]. https://www.ti.com/product/TMS320F28335 